Short Report

\title{
Experience with FLT3 Inhibitor Midostaurin in Newly Diagnosed Acute Myeloid Leukemia Patients
}

\author{
Mehmet BAYSAL ${ }^{1}$, Nihan ALKİS ${ }^{1}$, Serap BAYSAL ${ }^{2}$ \\ ${ }^{1}$ Bursa Şehir Hospital, Department of Hematology, Bursa, Turkey \\ ${ }^{2}$ Gürsu District Health Directorate, Bursa, Turkey
}

Keywords: AML, FLT3 mutation, Midostaurin

FMS-like tyrosine kinase 3 (FLT3) gene is located on the $13 \mathrm{q} 12$ chromosome. It is a member of the class III receptor tyrosine kinase (RTK) family that plays an important role in the proliferation and differentiation of hematopoietic stem cells. ${ }^{1}$ FLT3 mutation is seen in approximately $30 \%$ of newly diagnosed acute myeloid leukemia (AML) patients. ${ }^{2,3}$ FLT-internal tandem duplication (ITD) mutation was first reported in AML in 1996 by Nakao et al. ${ }^{4}$ These mutations disrupt the autoinhibitory function of the juxtamembrane of the receptor and result in the autophosphorylation of FLT3. ITD and tyrosine kinase mutation can be encountered in two different ways. FLT3 mutation is an important marker showing relapse and resistance to standard therapies in patients with AML. Patients with FLT3 ITD mutation or high allele burden of FLT3 ITD mutation; have lower mean survival rates compared to patients with negative FLT3 mutation. ${ }^{5}$ With the introduction of FLT3 inhibitors in recent years, the presence of FLT3 mutation in AML patients newly diagnosed has become more important. In the RATIFY study for which midostaurin, one of the FLT3 inhibitors, was approved by the FDA, it was observed that the addition of midostaurin to the remission induction and consolidation treatment provided a $22 \%$ reduction in mortality risk in patients with FLT3 mutation. ${ }^{6}$ In light of the above information, we aimed to share our experience and experience regarding the use of midostaurin in our newly diagnosed AML patients.

The data of 20 patients diagnosed with AML between April 2020 and November 2020 in the Hematology Department of Bursa City Hospital and who were eligible to receive standard remission induction therapy were evaluated retrospectively. Patients diagnosed with acute promyelocytic leukemia or who could not receive standard remission induction therapy because

Received:February 02,2021;Accepted:March 3,2021; Published Online:March 6, 2021 
of comorbidities and unfitness were excluded from the study. Standard remission induction chemotherapy consisting of a combination of cytosine arabinoside (ARA-C) and an anthracycline was applied to patients diagnosed with AML. While consolidation treatment with high dose ARA-C was applied to patients who were in remission; midostaurin $100 \mathrm{mg}$ daily was added to the patients with FLT3 mutation together with high-dose ARA-C between the $8^{\text {th }}$ and $21^{\text {st }}$ days in each cycle. Patients' characteristics, demographic information, and response status were retrospectively scanned from their files and hospital information system. Response status of patients was evaluated with bone marrow biopsies performed after remission induction chemotherapy. Standard criteria were used for response definitions. ${ }^{7}$ Complete response neutrophil count over $1,000 \times 10^{9} / \mathrm{L}$, platelet count over $100,000 \times 10^{9} / \mathrm{L}$, Independence from erythrocyte suspension transfusion, blast rate below $5 \%$, and complete maturation of all series (granulocyte, erythrocyte, and megakaryocyte) in bone marrow examination. ${ }^{7}$

Of the 20 patients included in the study, 14 were male and 6 were female. There were 6 patients with the FLT3 mutation. The frequency of FLT3 mutation among our patients was consistent with the current literature information. Five of the six patients with FLT3 mutation were male and one was female. The mean age of the patients is 53.8; The mean age of the patients with FLT 3 mutation was 49.8 years. The mean hemoglobin value of the patients at the time of diagnosis was $8.49 \mathrm{mg} / \mathrm{dL}$, the mean leukocyte count was $53,000 \times 10^{9} / \mathrm{L}$, and the mean platelet count was $56,650 \times 10^{9} / \mathrm{L}$. While two of our 6 patients with FLT 3 mutation died due to sepsis during remission induction treatment; in the other 4 patients, complete response was obtained with remission induction therapy. Four patients had been given midostaurin with high dose ARA-C and referred for bone marrow transplantation.

Risk classification in AML plays an important role in the planning of treatment. Molecular markers and mutations are included in the risk classification. It is known that AML patients with FLT3 mutations have shorter mean survival and progression-free survival rates. ${ }^{3,8}$ The use of FLT3 inhibitors together with chemotherapeutic agents in the treatment of AML patients with FLT3 mutation is considered as the standard approach. It is recommended to add FLT3 inhibitors along with standard remission induction therapy in patients with FLT3 mutation. ${ }^{9}$ However, it takes a certain amount of time for the FLT3 mutation to result. For this reason, midostaurin treatment could be added not during remission induction but consolidation. In addition to all these, when patients with FLT3 mutation enter remission, it is recommended to continue treatment with allogeneic hematopoietic stem cell transplantation. ${ }^{6,9}$ We directed our patients who were in remission and had suitable donors for allogeneic hematopoietic stem cell transplantation. Although our study included a limited number of patients, it shows the significance of midostaurin treatment in newly diagnosed AML patients with FLT3 mutation. FLT3 inhibitors will show their value as real-world data where targeted therapies are getting more and more important.

\section{Conflict of Interests}

Authors declare that there are none.

\section{Acknowledgment}

This study has been presented in $17^{\text {th }}$ Uludag Internal Medicine National Winter Congress, $6^{\text {th }}$ Bursa Family Medicine Association National Congress, $11^{\text {th }}$ Uludag Internal Medicine Nursing Congress, 5-7 March 2021, Bursa, Turkey.

\section{References}

1. Gilliland DG, Griffin JD. The roles of FLT3 in hematopoiesis and leukemia. Blood. 2002 Sep 1;100(5):1532-42. doi: 10.1182/blood-2002-02-0492.

2. Kottaridis PD, Gale RE, Frew ME, Harrison G, Langabeer SE, Belton AA, Walker H, Wheatley $\mathrm{K}$, Bowen DT, Burnett AK, Goldstone AH, Linch DC. The presence of a FLT3 internal tandem duplication in patients with acute myeloid leukemia (AML) adds important prognostic information to cytogenetic risk group and response to the first cycle of chemotherapy: analysis of 854 patients from the United Kingdom Medical Research Council AML 10 and 12 trials. Blood. 2001 Sep 15;98(6):1752-9. doi: 10.1182/blood. v98.6.1752.

3. Thiede C, Steudel C, Mohr B, Schaich M, Schäkel U, Platzbecker U, Wermke M, Bornhäuser M, Ritter M, Neubauer A, Ehninger G, Illmer T. Analysis of FLT3-activating mutations in 979 patients with acute 
myelogenous leukemia: association with FAB subtypes and identification of subgroups with poor prognosis. Blood. 2002 Jun 15;99(12):4326-35. doi: 10.1182/blood. v99.12.4326.

4. Nakao M, Yokota S, Iwai T, Kaneko H, Horiike S, Kashima K, Sonoda Y, Fujimoto T, Misawa S. Internal tandem duplication of the flt3 gene found in acute myeloid leukemia. Leukemia. 1996 Dec;10(12):1911-8.

5. Port M, Böttcher M, Thol F, Ganser A, Schlenk R, Wasem J, Neumann A, Pouryamout L. Prognostic significance of FLT3 internal tandem duplication, nucleophosmin 1, and CEBPA gene mutations for acute myeloid leukemia patients with normal karyotype and younger than 60 years: a systematic review and metaanalysis. Ann Hematol. 2014 Aug;93(8):1279-86. doi: 10.1007/s00277-014-2072-6.

6. Stone RM, Mandrekar SJ, Sanford BL, Laumann K, Geyer S, Bloomfield CD, Thiede C, Prior TW, Döhner K, Marcucci G, Lo-Coco F, Klisovic RB, Wei A, Sierra J, Sanz MA, Brandwein JM, de Witte T, Niederwieser D, Appelbaum FR, Medeiros BC, Tallman MS, Krauter J, Schlenk RF, Ganser A, Serve H, Ehninger G, Amadori S, Larson RA, Döhner H. Midostaurin plus chemotherapy for acute myeloid leukemia with a FLT3 mutation. N Engl J Med. 2017 Aug 3;377(5):45464. doi: 10.1056/NEJMoa1614359.

7. Döhner H, Estey EH, Amadori S, Appelbaum FR, Büchner T, Burnett AK, Dombret H, Fenaux P, Grimwade D, Larson RA, Lo-Coco F, Naoe T, Niederwieser D, Ossenkoppele GJ, Sanz MA, Sierra J, Tallman MS, Löwenberg B, Bloomfield CD; European LeukemiaNet. Diagnosis and management of acute myeloid leukemia in adults: recommendations from an international expert panel, on behalf of the European LeukemiaNet. Blood. 2010 Jan 21;115(3):453-74. doi: 10.1182/blood-2009-07-235358.

8. Ravandi F, Kantarjian H, Faderl S, Garcia-Manero G, O'Brien S, Koller C, Pierce S, Brandt M, Kennedy D, Cortes J, Beran M. Outcome of patients with FLT3mutated acute myeloid leukemia in first relapse. Leuk Res. 2010 Jun;34(6):752-6. doi: 10.1016/j. leukres.2009.10.001.

9. Estey EH. Acute myeloid leukemia: 2021 update on risk-stratification and management. Am J Hematol. 2020 Nov;95(11):1368-98. doi: 10.1002/ajh.25975. 